\title{
SOBRE LA REORGANIZACIÓN DE LA ALJAMA DE LOS JUDÍOS DE LÉRIDA (1400-1408)
}

\author{
MONTSERRAT CASAS NADAL \\ Universidad de Barcelona
}

\section{INTRODUCCIÓN}

Quisiera agradecer la invitación a participar en el merecido homenaje al profesor David Romano, de la Universidad de Barcelona. Quien esto escribe está en deuda con él, por su magisterio continuado desde hace muchos años, su consejo siempre oportuno y adecuado y por la amistad con que la distingue. Por todo ello desearía ofrecerle las primeras consideraciones sobre un tema al que he dirigido mis recientes investigaciones, sugerido por el propio prof. Romano, a raíz del primer Coloquio sobre Historia de los Judíos en la Corona de Aragón: la etapa final - la cuarta- de la aljama de Lérida, tras su restauración (redreç) después de las persecuciones de 1391 '. Pienso que el tema merece algún interés, especialmente si se tiene en cuenta que las aljamas de Lérida y Zaragoza ${ }^{2}$ fueron las únicas o las más importantes que consiguieron remontar las graves crisis de finales del siglo XIV.

Sirvan, pues, estas notas de adhesión incondicional al justo homenaje y de primera aproximación al problema de la restauración de la aljama leridana.

\section{LOS DOCUMENTOS}

Utilizo fundamentalmente dos documentos publicados por $F$. Baer, relativos a: 1) los capítulos otorgados por Martín I en el año

${ }^{1}$ D. Romano, "Els jueus de Lleida", Actes Ier Collogui d'Historia dels Jueus a la Corona d’Aragó, Lleida 1991, pág. 110.

2 A. Blasco, «Los judíos del reino de Aragón. Balance de los estudios realizados y perspectivas", Actes Ier Colloqui d"Historia dels Jueus a la Corona d'Aragó, Lleida, 1991, pág. 36. 
$1400{ }^{3}$ "per crear de nou aljama de juheus en la ciutat de Leyda", y 2) los capítulos de 1408, aprobados por el mismo rey, a instancia de Mossé Isaach Cotina, secretario de la aljama ilerdense ${ }^{4}$.

\section{CAPITULOS DE REDREC $(1400-1408)$}

Los capítulos de redreç para crear una nueva aljama en Lérida, nos permiten, de entrada, reafirmarnos en la idea de D. Romano de que no se trata propiamente de "ordenaciones" en el sentido clásico y preciso de la palabra, en tanto que no expresan una voluntad normativa y reguladora de la aljama, sino tan sólo fijan normas coyunturales para favorecer la repoblación de la Cuirassa s.

Los diversos capítulos son propuestas presentadas al rey Martín I

«ditionis nostre fuisse nobis reverenter oblata capitula, que secunturn ${ }^{6}$,

el cual las aprueba o las matiza con la típica fórmula del "capítol de cort»: "Plau al senyor Rey». En este tipo de textos jurídicos, la iniciativa legislativa corría a cargo de los súbditos o parte que presentaba la propuesta, propuesta que el monarca podía simplemente aprobar, corregir y disminuir, según las circunstancias.

\subsection{Concesiones con efecto retroactivo}

La variada gama de asuntos regulados en los capítulos de 1400 permite detectar una serie de medidas de efecto retroactivo. La más importante de ellas corresponde a la condonación de cuantas deudas pudieran haber contraído los componentes de la antigua aljama leridana, bien como comunidad, bien como individuos, con acreedo-

${ }^{3}$ F. BAER, Die Juden im christlichen Spanien. Urkunden und Regesten, Berlin 1929, reimpr. $1970[=J C S]$, doc. 472.

4 Ibid., doc. 480.

s Este es el nombre dado, por lo menos desde 1158, al ámbito espacial ocupado por la comunidad judía en Lérida. Vid. D. ROMANo, "Aljama frente a judería, call y sus sinónimos", Sefarad XXXIX (1979) 347-354.

${ }^{6}$ F. BAER, JCS, doc. 472, pág. 759. 
res ${ }^{7}$ tanto judíos como cristianos 0 moros ${ }^{8}$. Les era condonada también cualquier actuación criminal ${ }^{9}$ (el Rey exceptúa los típicos crímenes de lesa majestad, falseamiento de moneda y asalto de caminos), aunque se hubiese cometido en tierras baroniales o de abadengos ${ }^{10}$.

No menos interés tendría la reivindicación y recuperación de cuantos privilegios, inmunidades y libertades habían sido otorgados en épocas posteriores al asalto y destrucción de la judería. Los solicitantes no descartan que antiguos componentes de la aljama anterior acudieran a poblarla de nuevo, y «si algun sen pora trobar, sen puxa alegrar" ".

\subsection{Medidas de aplicación inmediata o futura}

Entre las medidas presentadas y aprobadas, con efectos futuros o inmediatos están las que afectan:

a) a la zona de hábitat,

b) a la economía y fiscalidad de la aljama,

c) a su administración y organización,

d) al vestido y señales externas de los miembros de la aljama.

\subsubsection{Relacionadas con la zona de hábitat}

El asalto a la Cuirassa de Lérida, en 1391, supuso por lo menos la muerte de setenta y ocho judíos, el bautismo de muchos otros y la conversión de la sinagoga en templo cristiano bajo la advocación de Nuestra Señora del Milagro ${ }^{12}$. A la vista de las reclamaciones de Isaac Cortina, secretario de la aljama, en 1408, la antigua sinagoga o "escola" continuaba siendo ocupada por el obispo de Lérida, si bien no ejercía ninguna función religiosa (

\footnotetext{
7 Entiendo la palabra "creadors", que transcribe Baer, en el sentido de 'acreedor', ibid., cap. 1 .

${ }^{8}$ Distingo estos tres grupos aunque no se especifica ninguna religión.

9 Ibid., cap. 4.

${ }^{10}$ Ibid., cap. 16.

$"$ Ibid., cap. 21.

12 D. Romano, «Els jueus", pág. 109.
} 
ecclesia ni es casa..." ${ }^{13}$ ); debía de ser un simple espacio o vivienda cuya propiedad se arrogó el obispo, Guerau de Requesens y de Montoliu, "sens licencia del senyor rey" después que «los hagues tirada e tolta la dita escola" ${ }^{14}$. Los judíos proponen como alternativa que se les indemnice adecuadamente $y$, con el dinero obtenido, construir una sinagoga nueva.

De hecho, en los capítulos presentados a la aprobación real se indica que

"per occasio de alguns no tement deu ne la correccio dela sua excellent senyoria avalotadament es venguda a final destruccio..." ${ }^{15}$,

y se incide aún en que

«... les cases e alberchs dela dita aljama son quaix caygudes, enderrocades e cremades..." ${ }^{16}$.

Ante la evidente destrucción física de la judería, los virtuales repobladores del nuevo barrio exigen y consiguen de Martín I que los propietarios eminentes de las casas (los denominados censaters $e$ trehuters) reconstruyan las viviendas en breve tiempo

«sian forçats e constrets dins breu temps, que adoben e tornen a degut stament les dites cases e alberchs en tal manera, que puxen en aquells habitar e star los juheus" ${ }^{17}$.

Se contempla la posibilidad de que los gastos de reparación pudieran correr a costa de los nuevos pobladores judíos, en detrimento de los propietarios del dominio directo o eminente ${ }^{18}$. Del grado máximo de destrucción de las casas de la Cuirassa es un claro testimonio la autorización a vivir fuera del mismo "per altres parts dela dita ciutat», en viviendas alquiladas a cristianos a precios justos y razonables

\footnotetext{
${ }^{13}$ F. BAER, JCS, doc. 480, cap. 2.

14 Ibid.

15 Ibid., doc. 472, cap. 1.

16 Ibid., cap. 2.

17 Ibid.

18 Ibid.
} 
"on los juheus qui alli vindran, puxen habitar e estar sens enpatxament e contrast algu» ${ }^{19}$;

la posibilidad de buscar vivienda fuera de la judería mientras durara su reconstrucción fue confirmada expresamente por los paheres de la ciudad el 6 de mayo de 1410, en una reunión del Consejo General ${ }^{20}$.

\subsubsection{Relativas a la economía y fiscalidad}

En el ámbito de la economía interna deben señalarse la anulación de deudas anteriores al gran asalto y destrucción de la judería, ya referidos, de suerte que la economía de la aljama y la de los particulares de la misma pudiera reiniciarse sin limitaciones ni cortapisas por herencias anteriores ${ }^{21}$.

Las garantías reales (guiatges) aseguran también a todos los futuros pobladores de la aljama ante cualquier deuda y por un período máximo de cinco años ${ }^{22}$ contables a partir del presente año, 1400

“... assegurar bastantment per $\mathrm{X}$ anys tot juheu o juhia, qui vindra $\mathrm{e}$ transportara son domicili en la dita aljama dela ciutat de Leyda, e a aquells, qui vuy hi stan, de qualsevol deutes, que degen ab carta o sens cartes..." ${ }^{23}$.

Por contra, se asegura en un período de diez años, que la justicia real no sobreseerá causa alguna por deudas contraídas por parte de cristianos o musulmanes, a fin de evitar dificultades económicas derivadas del impago de deudas:

«... no sobreseura ni alargara ... alguns cristians ni moros, que sien tenguts e obligats a pagar quals se vulla quantitats de moneda ara e en temps esdevenidor als juheus..." ${ }^{24}$.

\footnotetext{
19 Ibid., cap. 20.

20 P. Sanahuja, Lérida en sus luchas por la fe (judios, moros, conversos, inquisición $y$ moriscos), Lérida 1946, pág. 52.

${ }^{21}$ F. BAER, JCS, doc. 472 , cap. 1.

${ }^{22} \mathrm{La}$ comunidad pidió diez.

${ }^{23}$ Ibid., cap. 3.

24 Ibid., cap. 12.
} 
Se garantiza el cobro o recuperación de los préstamos realizados por judíos a favor de cristianos y musulmanes o, en su defecto, la apropiación de las prendas (penyores) en caso de divergencias con los prestatarios. A este fin se concede que la palabra del prestador judio se tenga por fiable tras haber prestado juramento sobre los diez mandamientos

«...quel dit juheu o juheus sien creeguts ab sagrament sobre los $x$ manaments, lo qual hagen affer en poder del batle dela dita ciutat..." ${ }^{25}$.

Se distingue perfectamente entre el capital prestado (cabal) y los intereses (guany); ambas cantidades podrán ser recuperadas en el plazo de diez días «segons es acustumat ales dites penyores", extendiéndose tal garantía incluso en caso de desaparición o hurto de la prenda ${ }^{26}$ :

"E encara sis dira esser la dita penyora o penyores furtada o furtades, ... que lavors lo dit juheu o juhia no puxa perdre son cabal ne son guany en alguna manera, axi com ja es acustumat en altres juheries" ${ }^{27}$.

La libertad de movimientos de personas y bienes de judíos, tanto si proceden de territorios de realengo como de abadengo o de señoríos baroniales, queda garantizada siempre y cuando cada persona singular que abandonara las ciudades, villas o lugares donde estaban radicados, de acuerdo con la aljama de origen o procedencia, después de haber valorado sus bienes, pague la parte correspondiente de censales y violarios que gravaren en aquel entonces su antigua aljama ${ }^{28}$.

En el ámbito estrictamente fiscal, los capítulos de redreç contemplan la exención de pagar una serie de impuestos estatales ${ }^{29}$ :

\footnotetext{
${ }^{25}$ Ibid., cap. 7.

26 Ibid.

27 Ibid.

${ }^{28}$ Ibid., cap. 8.

${ }^{29}$ Sobre este aspecto vid, D. Romano, «Els jueus", pág. 129.
} 
questies, demandes e imposicions, lits e quals se vulla atres carrechs" ${ }^{30}$,

por un período de seis años, mientras la aljama no consiga una población superior al centenar de familias (fochs o casats). En contrapartida, y para sufragar las múltiples necesidades internas, la aljama queda utorizada para imponer sisas y exacciones sobre el pan, vino, carne y otros comestibles, tal como había sido costumbre por parte de los antiguos miembros de la comunidad de Lérida, y de acuerdo con lo que pudieran decidir los secretarios de la aljama ${ }^{31}$. Se trata, por consiguiente, de facilitar recursos extraordinarios con vistas a que "la dita aljama se puxa mils poblar e reparar» ${ }^{32}$. Tal medida, autorizada en principio para un período de cinco años, se prorrogó por otros ocho más a raíz de las súplicas del secretario Mossé Issach Cortina, en 1408,

"en les quals imposicions haien a contribuir axi stranys com privats e les quals se haien a convertir en pagar los deutes e carrechs, que la dita aliama es o sera tenguda e obligada" ${ }^{33}$.

La solidaridad fiscal de todos los componentes de la aljama, sin exclusión alguna, se salvaguarda con el compromiso real de no eximir a nadie del pago, ni otorgar franquezas o privilegios a personas particulares, que pudieran conllevar el incremento de cargas fiscales sobre el resto de la comunidad:

«... aço redunda en dampnatge e prejudici no poch gran dela dita aljama" ${ }^{34}$.

Aquella solidaridad se ratificó en 1408 al obligar a

${ }^{30}$ F. BAER, JCS, doc. 472, cap. 6.

${ }^{31}$ Estas sisas o imposiciones son en algunos casos impuestos municipales. Hay que tener en cuenta - como recuerda D. Romano en "Els jueus", pág. 130- que los judíos no eran ciudadanos de Lérida, pero sí vecinos y «en remuneració del dit vehinatge paguen e haien a pagar a la Ciutat».

${ }^{32}$ F. BAER, JCS, doc. 472, cap. 18.

${ }^{33}$ Ibid., doc. 480, cap. 8. En las imposiciones, sisas o tallas que puedan gravar la comunidad tenían que intervenir tres personas, una de la mano mayor, otra de la mediana y otra de la menor, elegidas por los secretarios de la aljama. Ibid., cap. 6.

34 Ibid., cap. 11. 
«contribuir e pagar en tots donatius, messions e despeses, que faran los dits secretaris e los demes del consell en nom dela dita aliama" ${ }^{35}$,

sin excepción alguna.

\subsubsection{Relativas a la administración}

Las medidas de redrec de principios del siglo XV contemplan también la no menos importante problemática concerniente al ejecutivo de la aljama. Sobre esta cuestión todavía pende el dilema ${ }^{36} \mathrm{de}$ las diferencias - si es que las hay- entre secretarios, adelantados y regidores.

Curiosamente, a partir de todo este período de restauración, el ejecutivo deja de utilizar la tradicional denominación de "adenantats» 37 por el de «regidors» 0 «secretaris». El nombre de «regidor» posiblemente deba entenderse como autoridad o representante, en un sentido genérico, que los capítulos de 1400 cuidan mucho de especificar que «sian appellats secretaris dela aljama dels juheus de Leyda» ${ }^{38}$. Compete a estos secretarios: a) "fer aquellas bonas ordinacions, stabliments, que a profit de la dita aljama e juheus d'aquella los serà ben vist faedor»; b) ya hemos comentado su importancia en las decisiones de carácter económico y/o fiscal (vid. apartado 2.2.2); c) por lo menos a partir de 1408 , les compete «aiustar e ordenar e fer entre ells confraries..." ${ }^{39}$; d) también está entre sus atribuciones el nombrar los mensajeros judíos (missatge juheu) -y subrayo lo de judío en tanto que queda expresamente vetado para este cargo cualquier cristiano ${ }^{40}$ - con el cometido de que "faça los negocis dela dita aljama e dels juheus daquella»; e) los dos «secretaris» salientes deberán elegir cada año a sus sucesores, en tanto que el cargo - por lo menos en 1408 - era anual.

Respecto al Consejo (Consell), los capítulos presentados y aprobados en 1408 son bastante más explícitos que los de 1400. El

35 Ibid., doc. 480, cap. 12.

36 Apuntado por D. Romano en "Els jueus", pág. 115.

37 Denominación típica y propia de Lérida e insólita en el resto de Cataluña, pero usual en Aragón y Valencia. D. Romano, «Els jueus», pág. 116.

${ }^{38}$ F. BAER, JCS, doc. 427, cap. 9.

39 Ibid., doc. 480, cap. 13.

${ }^{40}$ Ibid., doc. 472, cap. 15. 
Consejo era elegido por los secretarios de la aljama y estaba compuesto por nueve miembros ${ }^{41}$, tres de cada mano o estamento.

Unos y otros (secretarios y consejeros) eran los legítimos representantes de toda la aljama y de cada uno de sus miembros. Les concierne

"fer tots actes e negocis expedients e necessaris ara e tostemps ala dita aliama a honor e utilitat del senyor rey e dela dita aliama" ${ }^{42}$;

citaremos como ejemplo: la creación de censales, distribución de sisas, pago de donativos, elección de representantes de cada mano encargados de

«hoyr, inpugnar, cautular, condempnar e diffinir leyalment e be los dits comptes" ${ }^{43}$,

o nombrar un notario con atribuciones similares a las de los notarios reales

" ... totes aquelles cartes, contractes e scriptures de qualsevulla specie sien que pendra, reebra o scriura ... hagen efficacia e valor en juhi e fora juhi, axi com si fos creat e confirmat per lo dit senyor rey" ${ }^{4}$.

Aparte queda la figura del baile real, a cuya autoridad están sometidos los judíos y la aljama leridana. El baile se encargaba de juzgar los procesos civiles y criminales entre judíos y cristianos 4 , ahorcar a los judíos malsines de la comunidad declarados como tales por la aljama y "segons la ley de juheus" "6, cobrar el «ban" $e$ impuestos destinados al Real Patrimonio, etc. ${ }^{47}$. En virtud de sus atribuciones, la comunidad en proceso de rehabilitación pidió que

${ }^{41}$ Eran diez en 1381, dieciocho en 1383 y nueve en 1410. Vid. D. Romano, «Els jueus», pág. 115.

${ }^{42}$ F. BAER, JCS, doc. 480 , cap. 5.

${ }^{43}$ Ibid., cap. 7.

4h El plácet real exige que para validar tales documentos cuenten con la roboración del baile real y sólo atiendan las relaciones entre judíos. Ibid., doc. 472, cap. 14.

${ }^{45}$ P. Sanahuja, op. cit., págs. 35-37.

46 F. BAER, JCS, doc. 480, cap. 4.

47 Tengo previsto estudiar este aspecto a través de los registros de Bailía General, sección del Real Patrimonio, del Archivo de la Corona de Aragón. 
"lo batle ... sia tengut jurar ... servar e complir los presents capitols e privilegis dela dita aljama ... sots pena de mil flor. dor als cofres del dit senyor» ${ }^{48}$.

Abusos de autoridad por parte del baile se aprecian en los capítulos de 1408, cuando el secretario de la aljama, Mossé Issach Cotina, denunciaba que tradicionalmente los bailes

"facen grans greuges moltes vegades a alguns presos de juheus, ço es, quels meten en la cija per no res, e la cija es humida e rellent daygua e es fort perillosa e preso no sia donada per torment, mas per custodia...." ${ }^{49}$.

\subsubsection{Relativas a los signos externos de los judíos}

Los capítulos de 1400 incluyen también una referencia a las obligaciones sobre la indumentaria. Los judíos estaban obligados a llevar ciertas prendas de ropa para distinguirse de los cristianos ${ }^{30}$. Ya el Concilio de Lérida de 1229, en su canon XVI, obligaba a todos los judíos a llevar capas cerradas (¿con capucha?) ${ }^{\text {s1. Las }}$ normas de 1400 deben de aludir a esta prenda cuando exime de llevar la rodela amarilla sobre sus vestidos, "sino en la forma e manera, que havian acustumat en temps passat" ${ }^{22}$; cabe suponer que "lo acostumbrado" a que alude la cita sean simplemente las referidas capas y capuchas. Me consta que, en 1436, el Consejo General de la Pahería exigió de nuevo a todos los hombres y mujeres judíos llevar, en lugar alto y bien patente, la rodela del tamaño de un "pan de sal» cosida al vestido y no prendida con un alfiler ${ }^{33}$.

48 Ibid., doc. 472, cap. 22.

49 Ibid., doc. 480 , cap. 3.

50 D. Romano, "Característiques dels jueus en relació amb els cristians en els estats hispànics", Jornades d'Història dels Jueus a Catalunya, Girona 1990, págs. 9-27. Dice al respecto: «Era establert que el jueu hagués de portar un senyal distintiu, normalment sobre el pit els homes; per a les dones no queda massa clar, però pels pocs exemples gràfics que tenim el portaven al front: és el que se'n deia normalment roda o rodela, amb una tendéncia al predomini del color groc, tot i que a Catalunya hi ha exemples també de vermell».

51 J. Lladonosa Pujol, Historia de Lleida, vol. 1, Tàrrega 1972, págs. 357.

32 F. BAER, JCS, doc. 472, cap. 17.

33 P. Sanahuja, op. cit., pág. 29. 


\section{COLOFón}

La serie de medidas que hemos descrito, así como la manifiesta voluntad real y aun la local para favorecer la restauración de la aljama ilerdense, debieron de tener resultados poco alentadores, como se desprende de la revisión de este asunto en 1421: la reina María, esposa de Alfonso el Magnánimo, en una carta dirigida a los paheres de Lérida afirmaba que

«és nostra intenció que en aquexa ciutat sie tornada població e aljama de juheus, segons debans solia ésser" ${ }^{54}$.

Otras disposiciones posteriores de la misma Lugarteniente, así como de Juan II, cuestionan - por lo menos- la eficacia del redreç. En cualquier caso, considero que este tema debe ser tratado en profundidad y con mayor extensión: sirvan estas notas como preludio de posteriores investigaciones.

\section{RESUMEN}

En este artículo se analizan dos documentos otorgados por Martín I de Aragón, en los años 1400 y 1408, a favor de la aljama de judíos de la ciudad de Lérida. Ambos documentos contienen normativas locales que afectan exclusivamente a la comunidad judía. Los capítulos otorgados por el monarca, a petición de los representantes de la aljama, están destinados a rehacer la aljama destruida, tanto física como institucionalmente, después del asalto de 1391. Los aspectos más relevantes de estas reformas y normas privilegiadas se refieren a la reconstrucción del espacio urbano y su repoblación, impulso de la economía, reforma de la administración y obtención de exenciones fiscales de forma temporal.

\section{SUMMARY}

Two documents, executed by the king Martin I of Aragon in 1400 and 1408 in favour of the Jewish aljama of Lerida, are analysed in this article. Both documents contain local regulations that exclusively concern the Jewish community. The chapters executed by the monarch, by request of the representatives of the aljama, are designed to rebuild the aljama that was destroyed, both physically and as an institution, after the assault of 1391 . The most relevant aspects of these privileged rules refer to the reconstruction and the repeopling process of the urban space, the impulse to the economy, the reformation of the Administration, and the attainment of temporary fiscal exemptions.

\$4 D. Romano, «Els jueus», pág. 110. 